\title{
Chapter 26 \\ Risk Reduction as a Result of Implementation of the Functional Based IMO Polar Code in the Arctic Cruise Industry
}

\author{
Knut Espen Solberg, Robert Brown, Eirik Skogvoll, \\ and Ove Tobias Gudmestad
}

\begin{abstract}
The IMO Polar Code states that equipment and systems providing survival support for passengers/crew should have adequate thermal protection for a minimum of 5 days. Based on participant workshops where suppliers, regulators, users and academia were present, the following three functionality requirements were identified as essential for survival: Maintaining cognitive abilities; No uncontrollable body shivering and Functionality of extremities.

Following the participant workshops, a field trial was conducted in Wood Fjord, Northern Svalbard, during the last week of April 2016. The goal of the trial was to identify the gaps in functionality provided by life-saving equipment currently approved by SOLAS and the functionality required to comply with the minimum requirement of 5 days survival, according to the IMO Polar Code.

The trial demonstrated that when utilizing standard SOLAS approved equipment, compliance with the functional Polar Code requirement of protection from hypothermia cannot be expected beyond $24 \mathrm{~h}$ of exposure.
\end{abstract}

\footnotetext{
K.E. Solberg $(\triangle) \bullet$ O.T. Gudmestad

Mechanical and Structural Engineering and Materials Science, Faculty of Science and Technology, University of Stavanger, Stavanger, Norway

e-mail: Knut.Espen.Solberg@gmc.no

R. Brown

Ocean Safety Research, Marine Institute, Memorial University, St. John's, Canada

E. Skogvoll

Faculty of Medicine, Norwegian University of Science and Technology (NTNU),

Trondheim, Norway
} 


\subsection{Introduction}

Cruise ship activity in polar regions has increased in recent years and the trend is expected to continue. With the successful transit of the Crystal Serenity through the Northwest Passage in 2016, there are currently several expedition cruise vessels being commissioned. The increase in the cruise ship industry is also expected to take place around the Svalbard island (Brunvoll 2015).

The International Code for Ships Operating in Polar Waters (The IMO; International Maritime Organization Polar Code) is a supplement to existing IMO instruments, and the intention is to mitigate the additional risks present for people and environment when operating vessels in polar waters (International Maritime Oranization 2016). The code enters into force on 01.01.2017 for newbuilds, and on 01.01.2018 for existing vessels.

Contrary to most of the existing IMO instruments, the International Code for Ships Operating in Polar Waters provides a risk-based approach (ABS 2016) to regulating activity in this area. This means that marine operators are to identify risks and mitigate them through a holistic approach.

According to IMO Polar Code, Chapter 8 - Life-saving appliances and arrangements, the life-saving equipment is to provide adequate functionality to ensure human survival for a minimum of 5 days for the anticipated weather conditions (cold and wind) and potential for immersion in polar water.

In an effort to better understand the performance requirements for polar survival equipment, a set of field trials was undertaken with human participants in Wood Fjord, Northern Svalbard in the last week of April 2016.

The goal of the field trials was to identify the gaps in functionality provided by regular SOLAS approved life-saving equipment and the functionality required to comply with the minimum requirement of 5 days survival, according to the IMO Polar Code (Solberg et al. 2016).

\subsection{Methods}

Two life saving appliances (LSAs) were deployed to the water surface - a 25 person life raft and 50 person lifeboat with 19 and 18 participants, respectively. The participants were mainly personnel from the Coast Guard. The majority of the participants were young men in their early 20s. Due to their training from the Coast Guard, they were accustomed to cold climate conditions and were in general physically fit (completed a $3000 \mathrm{~m}$ run in less than $15 \mathrm{~min}$ ).

All participants wore long woolen underwear under regular shirts and pants. The participants were equipped with different types of SOLAS approved personal protective equipment (PPE). The following gear was utilized:

Neoprene survival suit - Neoprene survival suit with integrated soles, 4 pieces. Insulated survival suit - Insulated survival suit with integrated soles, 6 pieces. 
Non-insulated survival suit - Non-insulated survival suit with integrated soles, 5 pieces.

Thermal protection vest - Standard SOLAS approved thermal protection vest/aid, 6 pieces.

Kampvest with bag - The standard life jacket utilized by the Norwegian Coast Guard. The participants stayed inside a plastic bag (TPA-Thermal Protection Aid), 6 pieces.

Kampvest without bag - The standard life jacket utilized by the Norwegian Coast Guard, 4 pieces.

Nordkapp drakt - The offshore working suit utilized by the Norwegian Coast Guard. The suit with integrated steel toe boots, and loose neoprene gloves, 2 pieces.

Survival suit 307 - The standard survival suit utilized by the Norwegian Coast Guard with integrated soles, 2 pieces.

The participants were constantly monitored by medical personnel and were omitted from the trial when any of the following predefined criteria were met:

- Loss of cognitive abilities

- Loss of body control (uncontrollable shivering)

- Loss of functionality of body extremities

When the participants commenced the exercise, they were warm and dry. There was no water present in the rescue crafts on commencement of the exercise. Introducing water inside the rescue craft would significantly have reduced the participants' survival time (DuCharme 2007).

During the exercise, body core temperatures were monitored and recorded for selected participants. All participants went through a medical examination immediately after aborting the exercise, where cognitive abilities, functionality and body temperature were assessed and documented.

\subsubsection{Exercise Validity}

The intent of the exercise was to simulate a cruise ship incident during the cruising season in Svalbard. The following boundary conditions were observed:

- Average ambient air temp $=-9^{\circ} \mathrm{C}$

- Average wind speed $=2 \mathrm{~m} / \mathrm{s}$

- Water temperature $=-1.2{ }^{\circ} \mathrm{C}$

- Participant health $=$ above average

- Participant insulation layer = average

- Additional stress factors $=$ marginal

A higher wind speed would be expected to reduce the survival times considerably and the weather conditions observed should be regarded as a "best case". 


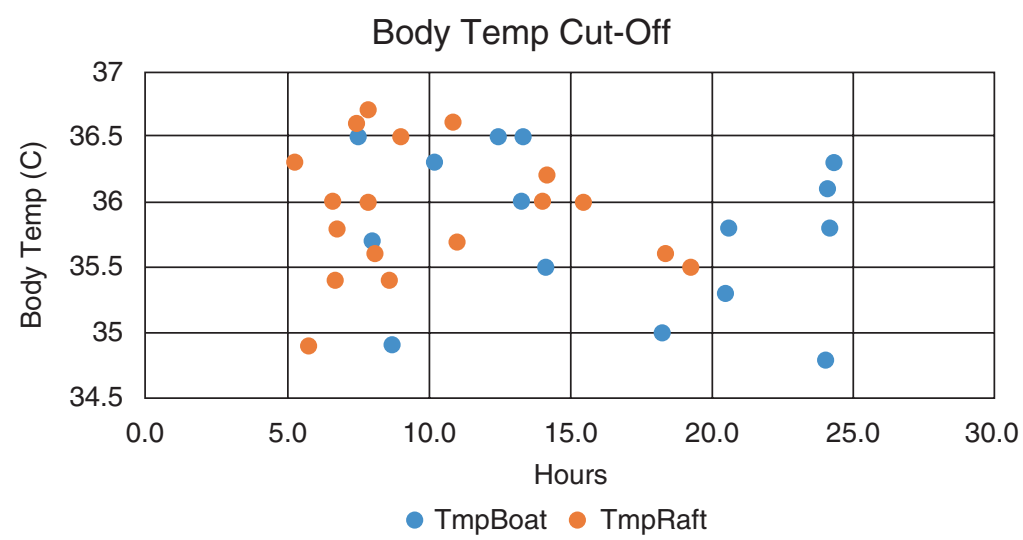

Fig. 26.1 Body Temp Cut-Off - the individual body temperatures at time of abandoning the exercise

As the participants were, on average, not only younger but also fitter than the average cruise ship passenger, the participants' physical condition gave them a higher probability for survival.

The abortion criteria gave a consistent cut-off point for participants, with all aborting the exercise with a core body temperature between $34.7^{\circ} \mathrm{C}$ (mild hypothermia) and $36.7^{\circ} \mathrm{C}$ (normal) (Fig. 26.1).

In a real scenario, most survivors would be very strongly motivated to stay alive and would be expected to survive for an extended period after our abortion criteria were met. It is however unlikely that the majority of the participants would survive for another 4 days, as required by the Polar Code, using equipment currently approved by SOLAS.

\subsection{Results and Discussion}

Based on the Kaplan-Meier Survival Plot (Fig. 26.2) it was evident that the cooling process started immediately after the exercise commenced. The first participants aborted the exercise from the raft after about $6 \mathrm{~h}$.

Eight hours into the exercise, the engine in the lifeboat was turned off, removing an essential heat source. After this point in time, neither of the LSAs had a heat source, except what was generated by the participants.

In the life raft, the last participants aborted the exercise after $19 \mathrm{~h}$, while several persons remained in the lifeboat after $24 \mathrm{~h}$. 


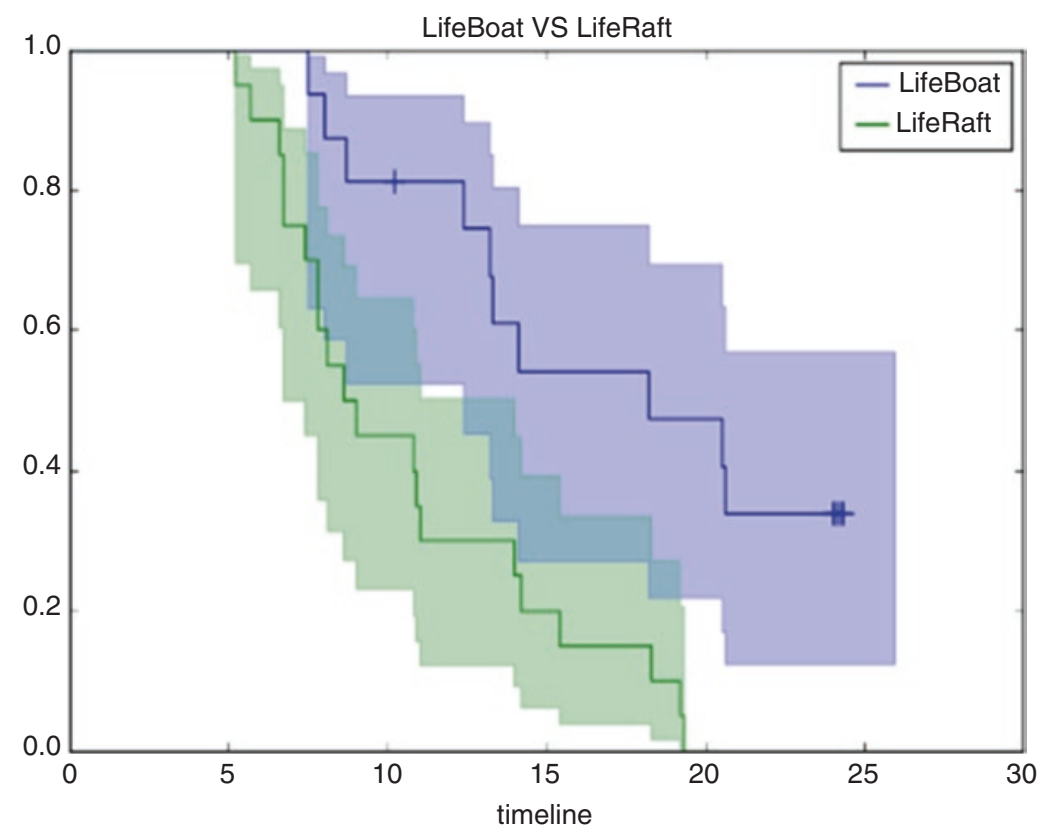

Fig. 26.2 Kaplan-Meier Survival Plot - indicating the fraction of participant survival on the Y-axis and the time spent in the rescue craft in hours on the $\mathrm{X}$-axis (based on abortion criteria)

\subsubsection{Hazard Curve}

The data from the lifeboat plotted as a hazard curve (with confidence interval) shows that the highest hazard was experienced after about $15 \mathrm{~h}$. At around this time, the rate of participants leaving the exercise was at its highest (Fig. 26.3).

The hazard curve for the lifeboat has distinct features: a period of low hazard, a period of increasing hazard and a period of decreasing hazard. For the life raft, the same features could be identified but by the time the life raft reached the survival phase, no participants were left.

The analysis of the hazard curve was broken down into three different phases (Fig. 26.3).

\subsubsection{Stage 1-Cooling Phase}

During the first $7.5 \mathrm{~h}$, all participants remained in the life-boat. Everyone was well fed, dry and warm prior to entering the rescue craft. In this phase, the participants became accustomed to their situation. During this period, the social structure was established with the lifeboat captain, including a plan on how to distribute resources, e.g. water in addition to distribution of responsibilities, e.g. keeping lookout. 


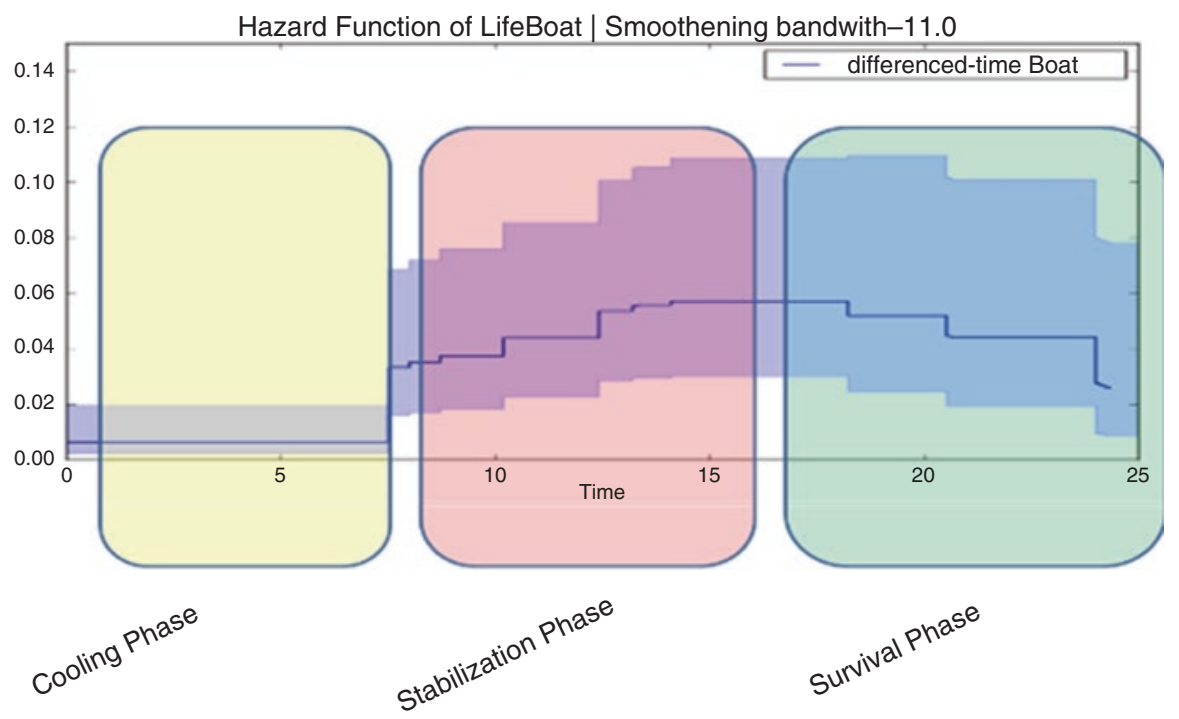

Fig. 26.3 Rescue Craft Phases - an illustration of the different phases, cooling phase (yellow), stabilization phase (red) and survival phase (green), with the timeline (hours) on the $\mathrm{X}$-axis and the Hazard coefficient on the Y-axis for the lifeboat

During this phase, the participants were exposed to the cold natural environment, with an ambient air temperature of about $-9{ }^{\circ} \mathrm{C}$ and a sea water temperature of $-1.2^{\circ} \mathrm{C}$.

\subsubsection{Stage 2-Stabilization Phase}

From about $7.5 \mathrm{~h}$ into the exercise, participants were starting to abort the exercise. The rate increased steadily until it reached its peak at about $16 \mathrm{~h}$.

Those first to leave were in general participants with only life vests/thermal protective aids. Many of them being wet, typically from condensation inside the rescue craft. The moisture caused an increased heat loss due to evaporative and conductive cooling, which reduces the insulating capabilities of the clothes.

Several also left the exercise early due to significant cooling of their extremities, with the most dominant area of concern being the hands. Cooling of the hands occurred typically because of conducting tasks that required fine motor skills, e.g. opening/closing zippers and opening water bags.

The lifeboat engine was turned off $8 \mathrm{~h}$ into the exercise. To increase the internal air temperature, hatches remained closed for the majority of the time. $\mathrm{CO}_{2}$-level meters showed an alarmingly high $\mathrm{CO}_{2}$ concentration, and the craft had to be ventilated about every $15 \mathrm{~min}$, depending on the number of participants on board. This process contributed to reducing the interior air temperature. Low $\mathrm{O}_{2}$-levels also turned out to be a major concern for the participants in the life raft as identified in previous projects (Baker Andrew et al. n.d.). 


\subsubsection{Stage 3-Survival Phase}

From $16 \mathrm{~h}$ onwards, the rate at which participants aborted the exercise slowly decreased until the trial was complete after $24 \mathrm{~h}$. As participants left the rescue craft, space was made available, giving the remaining participants the opportunity to move, generate heat and increase the blood flow to the extremities. The reduced number of persons on board also decreased the need for venting due to increased $\mathrm{CO}_{2}$ levels.

This far into the exercise the participants were starting to feel fatigue, which resulted in an urge to lie down and rest. Substantial heat loss was experienced from the body parts that were in contact with the cold surfaces inside the rescue crafts. This again resulted in abortion criterion Pt. 2 being met.

By the time the rescue craft had reached Phase 3, the survival phase, the following conditions essential for improving survivability had emerged: Sufficient space to allow movement; Reduced $\mathrm{CO}_{2}$ levels inside rescue crafts; Established rescue craft routines, giving the participants the ability to predict and remain in "control" of the situation.

\subsubsection{Habitable Environment}

When a rescue craft is filled with close to $100 \%$ of its capacity, the heat generated by the occupants results in a relatively high internal air temperature (Fig. 26.4). From the figure it is also evident that the heat generated by the lifeboat engine adds a significant amount of heat, keeping the internal air temperature stable until it is turned off at about $500 \mathrm{~min}$ into the exercise.

The temperature reductions observed at regular intervals for the life raft-curve are a result of the occasions when the participants opened the canopy for venting.

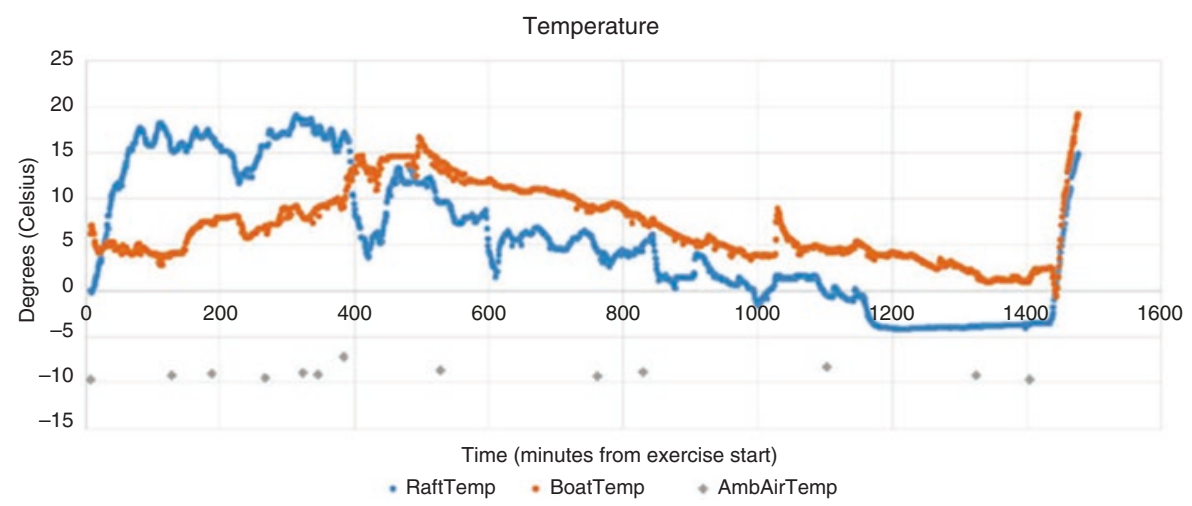

Fig. 26.4 Internal air temperature - the internal air temperature inside the rescue crafts 
No Persons Raft vs AirTemp Raft

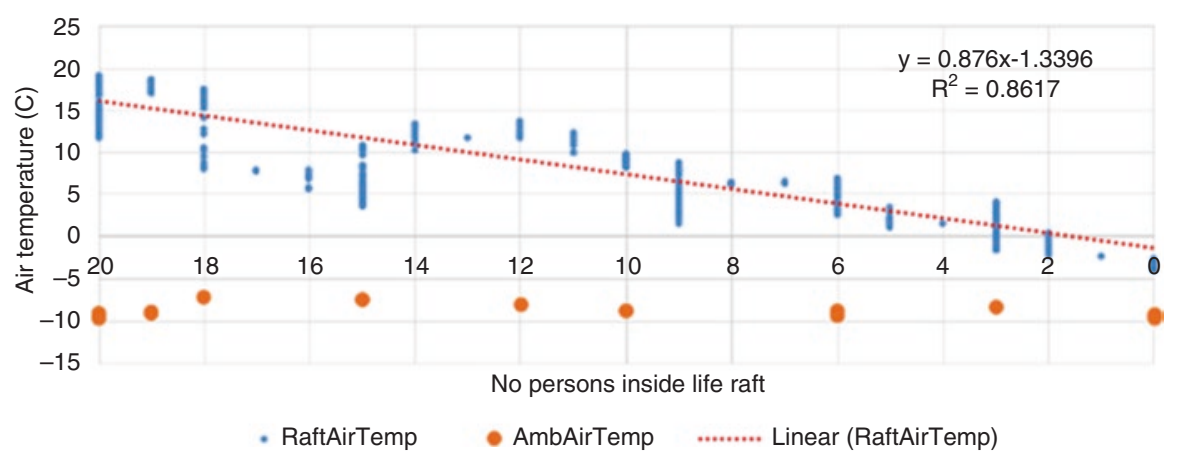

Fig. 26.5 Air Temperature vs. People in the Raft - the internal air temperature is plotted in relation to the number of people inside the life raft

The ambient outside air temperature for the duration of the exercise was relatively steady at between -7 and $-10{ }^{\circ} \mathrm{C}$. The decrease in the interior temperature is correlated to the number of persons present inside the rescue craft. This relationship is clearly visible in Fig. 26.5: Air Temperature vs. People in the Raft.

Lack of space resulting in lack of ability to move body limbs was also identified as a major challenge by the participants during the post exercise interviews. The reduced ability to move caused a lack of blood circulation. SOLAS approved LSAs are dimensioned for an average person with a weight of $75 \mathrm{~kg}$ and a shoulder breadth measurement of $400 \mathrm{~mm}$. Our identification of lack of space harmonizes with the research done by (Kozey et al. 2008/2009). Based on measurements of offshore workers in Eastern Canada wearing marine abandonment immersion suits they recommend downgrading the rescue craft capacity by approximately $15 \%$ to accommodate the actual size of occupants wearing insulated PPE.

\subsubsection{Rescue Craft Moisture}

Moisture in the insulation layers of PPE reduces its effective insulation value and has a detrimental effect on the survival rate (Michel B. DuCharme et al. n.d.). All participants were wet when they aborted the exercise. In respect of the participants wearing survival suits, the moisture came from their own body's perspiration. The participants wearing only life jackets experienced moisture accumulating in their clothing from the condensation inside both rescue crafts. This moisture inside the life raft caused great concern as it condensed on the inside of the canopy and accumulated on the floor of the raft where people were sitting. 


\subsubsection{Additional Stress Factors}

Prior to the trial, all participants were briefed on the risks involved and the safety system in place.

When a walrus appeared in the exercise area, only a few meters from the raft, the participants in the life raft had to keep a sharp lookout, and the canopy had to remain open for a prolonged period. Normal routines also had to be abandoned. This diverted the participants' focus from staying warm and resulted in a few participants having to abort the exercise.

On board the lifeboat, one person had to stay outside for some time to assemble the radar reflector, usually a short and uncomplicated task. Due to the cumbersome survival suit, neoprene gloves, cold metal parts and snow on the deck, this job took longer than usual. The participant also had to remove his gloves to complete the task, resulting in cooling of the extremities and degraded fine motor control. Despite returning to the lifeboat, he did not recover the use of his hands and had to abort the exercise some time later.

The ability to manage additional tasks will in many cases cause additional stress. The majority of the participants were focused on staying warm. In a cold climate survival situation, conducting additional tasks that divert the focus from staying warm, will reduce the probability of survival.

\subsubsection{Psychological Aspects}

In a real situation, the motivation to survive will likely be stronger than in an exercise scenario, but there will also be additional stress factors. All participants expressed the importance of a well-trained lifeboat/life raft captain. This person has a key role in establishing routines and distributing the available resources. The captain of the rescue craft also has an important role in creating routines and predictability. This is of key importance for remaining motivated and utilizing the individual resources in a sustainable manner.

Confident leadership will greatly influence the survival rate of those on a rescue craft. The longer the stay in the craft, the more important is the leadership.

\subsubsection{Personal Protection}

Assessing the different PPE based on time spent in the LSA gives an indication of the relative functionality of the equipment and how well it protects the participants. See Table 26.1: Personal Protective Equipment for more information. The different types of PPE offered different levels of protection, however, it is clear that the survival suits gave a major advantage over the different types of vests. 
Table 26.1 Personal Protective Equipment - the hours that people stayed in the rescue crafts utilizing different personal protective equipment

\begin{tabular}{l|l|l|l|l|l|l|l|l}
\hline & $\begin{array}{l}\text { Survival } \\
\text { Suit } \\
\text { Neopren }\end{array}$ & $\begin{array}{l}\text { Survival } \\
\text { Suit } \\
\text { Insulated }\end{array}$ & $\begin{array}{l}\text { Survival } \\
\text { Suit } \\
\text { non- } \\
\text { Insulated }\end{array}$ & $\begin{array}{l}\text { Thermeal } \\
\text { protection } \\
\text { West }\end{array}$ & $\begin{array}{l}\text { Kamp- } \\
\text { vest } \\
\text { with } \\
\text { bag }\end{array}$ & $\begin{array}{l}\text { Kamp- } \\
\text { vest no } \\
\text { bag }\end{array}$ & $\begin{array}{l}\text { Nordkap } \\
\text { Drakt }\end{array}$ & $\begin{array}{l}\text { Survival } \\
\text { Suit 307 }\end{array}$ \\
\hline $\begin{array}{l}\text { Average } \\
\text { Life } \\
\text { boat (h) }\end{array}$ & 22.3 & 22.3 & 16.0 & 11.0 & 15.2 & 10.0 & 24.3 & \\
\hline $\begin{array}{l}\text { Average } \\
\text { Raft (h) }\end{array}$ & 7.6 & 17.5 & 14.4 & 6.4 & 8.6 & 6.0 & 13.2 & 9.4 \\
\hline
\end{tabular}

While the number of participants within each test condition makes it difficult to state findings as being statistically significant, the results still point to performance gaps between protective survival equipment currently approved through SOLAS and what is now required by the Polar Code.

The large discrepancy for the neoprene survival suit between the lifeboat and the life raft was due to water ingress in the suits. The leaks were not experienced as a problem in the lifeboat, while in the life raft the leaks caused wetness, with a loss of insulating capability in the layers of clothes.

Stochastic studies predict a 50\% probability of survival when immersed to the neck in $5^{\circ} \mathrm{C}$ water for about $3 \mathrm{~h}$ in heavy seas, wearing a long-sleeved shirt, light sweater, and jacket (Tikuisis and Keefe 2005). Few studies have however been conducted, investigating the long term effects of heat production caused by shivering response, and there are limited predictive models for long-term exposure to cold (Xu et al. 2005). Significant individual variations with regards to the ability to produce heat induced by the body's shivering response represents a large spread in the data material.

\subsection{Conclusions}

The trial described here was the first of its kind to be carried-out in the field since publication of the IMO Polar Code. Results suggest that there are gaps in performance for survival equipment currently approved by SOLAS compared to what is required by the Polar Code. It is clear that individual motivation and knowledge play an important role in a survival scenario. Conducting simple tasks like unzipping the survival suits at regular intervals for ventilation and drying out the insulating layer can greatly influence the outcome for that individual. The Polar Code 
states that equipment is to protect the passengers/crew from hypothermia. When utilizing standard SOLAS approved equipment, compliance with the functional Polar Code requirement of protection from hypothermia is not expected beyond 24 $\mathrm{h}$ of exposure in relatively benign polar conditions. With few exceptions, all of the participants had reached the abortion criteria well before $24 \mathrm{~h}$. In a real accident scenario, the participants would have survived for an extended period beyond this point, but for how long is uncertain.

It is very unlikely, however, that a majority of the participants would have survived inside the LSAs for another four days, due to continued loss of core temperature and few opportunities for heat generation. To increase the survival rate, modifications to the functionality of the equipment would be required. These include:

- Higher degree of insulation in the personal protective aids

- A defined level of insulation in survival craft to balance the expected heat loss and ventilation needs for extended survival in polar regions

- Increased space per person to enable movement to ensure blood circulation

- $\mathrm{CO}_{2}$ measurement devices/alarms inside the rescue craft

- Active ventilation systems to ensure a safe microclimate inside the rescue craft

- Larger and extended range of food and water rations

- Enhanced training of lifeboat/liferaft captains for long term survival situations in polar regions

\section{References}

ABS (2016) IMO polar code advisory. Huston, American Bureau of Shipping (ABS)

Andrew B et al (n.d.) Carbon dioxide accumulation within a totally enclosed motor propelled survival craft. Memorial University/National Research Council Institute for Ocean Technology, St. John's

Brunvoll R (2015) MASTERPLAN Svalbard mot 2025. Sysselmannen Svalbard. Hentet fra http://www.sysselmannen.no/Documents/Svalbard_Miljovernfond_dok/Prosjekter/Rapporter/ 2015/14-\%2020\%20Masterplan\%20Svalbard\%20mot\%202025.pdf

DuCharme ME (2007) Effect of wetness and floor insulation on the thermal responses during cold exposure in a life raft. In: Proceedings of 12 international conference on Environmental Ergonomics, Piran Slovenia

DuCharme MB, Evely K-A, Basset F, MacKinnon SN, Kuczora A, Boone J, Mak L (n.d.) Effect of wetness and floor insulation on the thermal response during cold exposure in a liferaft. Defence R\&D Canada, Quebec City

International Maritime Oranization (2016) POLAR code, international code for ships operating in polar waters. IMO Publishing, London, ISBN 978-92-801-1628-1.

Kozey JW et al (2008/2009) Effects of human anthropometry and personal protective equipment on space requirements. Occupational Ergonomics 8:67-79 
Solberg et al. (2016) SARex Spitzbergen, Search and rescue exercise conducted north of Spitzbergen, Exercise Report. University of Stavanger, Stavanger. ISSN 0806-7031/ISBN 97882-7644-677-7. Hentet fra https://brage.bibsys.no/xmlui/handle/11250/2414815

Tikuisis P, Keefe AA (2005) Stochastic and life raft boarding predictions in the Cold Exposure Survival Model (CESM v3.0). Defence Research and Development Canada, Toronto

Xu X, Tikuisisb P, Gonzaleza R, Giesbrechtc G (2005) Thermoregulatory model for prediction of long-term cold exposure. Computers in Biology and Medicine 35:287-298

Open Access This chapter is licensed under the terms of the Creative Commons Attribution 4.0 International License (http://creativecommons.org/licenses/by/4.0/), which permits use, sharing, adaptation, distribution and reproduction in any medium or format, as long as you give appropriate credit to the original author(s) and the source, provide a link to the Creative Commons license and indicate if changes were made.

The images or other third party material in this chapter are included in the chapter's Creative Commons license, unless indicated otherwise in a credit line to the material. If material is not included in the chapter's Creative Commons license and your intended use is not permitted by statutory regulation or exceeds the permitted use, you will need to obtain permission directly from the copyright holder.

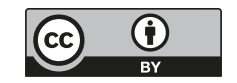

